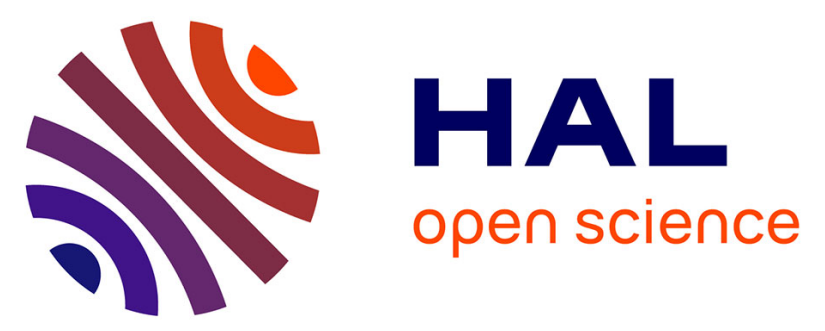

\title{
Chemistry on the electrodes: post-functionalization and stability enhancement of anchored dyes on mesoporous metal oxide photoelectrochemical cells with copper-free Huisgen cycloaddition reaction
}

Yousra Bentounsi, Konstantinos Seintis, Dorine Ameline, Stephane Diring, David Provost, Errol Blart, Yann Pellegrin, Damien Cossement, Eric Vauthey, Fabrice Odobel

\section{- To cite this version:}

Yousra Bentounsi, Konstantinos Seintis, Dorine Ameline, Stephane Diring, David Provost, et al.. Chemistry on the electrodes: post-functionalization and stability enhancement of anchored dyes on mesoporous metal oxide photoelectrochemical cells with copper-free Huisgen cycloaddition reaction. Journal of Materials Chemistry A, 2020, 8 (25), pp.12633-12640. 10.1039/D0TA04982D . hal-02991679

\author{
HAL Id: hal-02991679 \\ https://cnrs.hal.science/hal-02991679
}

Submitted on 20 Nov 2020

HAL is a multi-disciplinary open access archive for the deposit and dissemination of scientific research documents, whether they are published or not. The documents may come from teaching and research institutions in France or abroad, or from public or private research centers.
L'archive ouverte pluridisciplinaire HAL, est destinée au dépôt et à la diffusion de documents scientifiques de niveau recherche, publiés ou non, émanant des établissements d'enseignement et de recherche français ou étrangers, des laboratoires publics ou privés. 


\title{
Chemistry on the electrodes: post-functionalization and stability enhancement of anchored dyes on mesoporous metal oxide photoelectrochemical cells with copper-free Huisgen cycloaddition reaction
}

\author{
Yousra Bentounsi, ${ }^{a}$ Konstantinos Seintis,,${ }^{b}$ Dorine Ameline, ${ }^{a}$ Stéphane Diring, ${ }^{a}$ David \\ Provost, ${ }^{a}$ Errol Blart, ${ }^{a}$ Yann Pellegrin, ${ }^{a}$ Damien Cossement, ${ }^{{ }^{c}}{ }$ Eric Vauthey ${ }^{* b}$ Fabrice \\ Odobel $* a$
}

${ }^{a}$ Université de Nantes, CNRS, CEISAM UMR 6230, F-44000 Nantes, France. E-mail: Fabrice.Odobel@univ-nantes.fr

Department of Physical Chemistry, University of Geneva, 30 Quai Ernest-Ansermet, CH-1211

Geneva, Switzerland.E-mail:Eric.Vauthey@unige.ch

${ }^{c}$ Materia Nova Research Center, Parc Initialis, 1, Avenue Nicolas Copernic, B-7000 Mons, Belgium.E-mail: Damien.Cossement@materianova.be

\begin{abstract}
Hybrid materials consisting of nanocrystalline metal oxide films coated with molecules have considerable implications for the development of optoelectronic devices. We report on a straightforward and versatile procedure to engineer stable layers made of molecules chemisorbed on the surface of mesoporous inorganic metal oxides. The procedure is based on a thermal copper-free Huisgen reaction, which is directly conducted on $\mathrm{TiO}_{2}$ or $\mathrm{NiO}$ nanocrystalline films, between already bound diketopyrrolopyrrole sensitizers substituted by two azido groups and a crosslinking agent consisting of a tetrapropiolate ester. The procedure is mild and simple and does not require a catalyst, since quantitative conversion is obtained by a simple heating of the photoelectrode into a solution of the crosslinking agent. The photoelectrodes were characterized by ToF-SIMS, femtosecond transient absorption spectroscopy, electrochemistry and were finally used to fabricate dye-sensitized solar cells with iodide/triiodide and cobalt trisbipyridine complexes as redox mediators. Important increased stability of the crosslinked films were demonstrated by desorption and cyclic voltammetry experiments. Transient absorption spectroscopy and photovoltaic measurements showed that the dyes keep their initial photoelectrochemical properties upon crosslinking. This bottom-up approach is certainly broadly applicable and opens the possibility to make "chemistry on the electrode" to functionalize and crosslink dyes with any component.
\end{abstract}

Keywords: click chemistry; dye-sensitized solar cell; photoelectrochemical cell; crosslinking; surface functionalization.

The immobilization of dyes on nanocrystalline films of metal oxides (conductor or semiconductor) has considerable implications for the development of innovative devices for photovoltaics, artificial photosynthesis, sensors and molecular electronics. They lie at the heart of dye sensitized solar 
cells (DSSCs), ${ }^{1}$ dye-sensitized photoelectrosynthetic cells (DSPECs) ${ }^{2-5}$ and photo-rechargeable batteries. ${ }^{6}$ These devices generally consist of a mesoporous film made of nanoparticles of a metal oxide coated with a monolayer of a molecular system. However, as far as the stability is concerned, the desorption of the dyes or dye-catalyst assembly from the metal oxide surface in electro- and photoelectrocatalytic systems still represents an important issue, which is far from being solved. ${ }^{7}$ A variety of linkage strategies have been used to bind dyes or molecular assemblies onto oxide surfaces. ${ }^{7,8}$ Carboxylic acid group is most used anchor (particularly in DSSCs), but carboxylates typically hydrolyze from the surface in aqueous media. ${ }^{9}$ Immobilization via phosphonic acid derivatives is more robust, but still suffers from long-term instability. ${ }^{10,11}$ Some recent studies present results, which show that alkoxysilane $^{12-14}$ and hydroxamic acid ${ }^{15,16}$ derivatives may provide even higher stabilities than phosphonate linkages. However, for practical utility, a photoelectrochemical device for DSPECs or DSSCs has to be stable during very long periods of operation, even in aqueous solutions, and over an extended $\mathrm{pH}$ range. Several strategies were explored to increase the stability of the immobilized dyes. In DSSCs, radical polymerization of dyes bearing vinyl or alkyne groups by UV irradiation proved to be efficient to reduce the desorption kinetic. ${ }^{17-19}$ In DSPECs, Meyer and co-workers have developed two ingenious procedures, which effectively stabilize the dyes upon desorption. One approach is based on the electro-polymerization of initially immobilized sensitizers (usually ruthenium polypyridine complexes) containing vinyl substituents in presence of a substrate (such as a water oxidation catalyst) also bearing vinyl groups. Applying a negative potential to the $\mathrm{TiO}_{2}$ film brings about the electroreduction of the dyes and induces the formation of an electropolymerized overlayer of the substrates onto the sensitizers. ${ }^{2}{ }^{20}$ In the same vein, Zhong and co-workers take advantage of the oxidative coupling of arylamines to bridge adjacent sensitizers grafted on $\mathrm{TiO}_{2}$ which enhances the stability towards desorption. ${ }^{21}$ The second more subtle approach reported by Meyer and co-workers makes use of metal phosphonate chemistry. ${ }^{22}$ For example, a sensitizer substituted by multiple phosphonic acid groups $\left(\mathrm{PO}_{3} \mathrm{H}_{2}\right)$ is chemisorbed on the surface of a mesoporous $\mathrm{TiO}_{2}$ film. In a second step, the free $\mathrm{PO}_{3} \mathrm{H}_{2}$ of the dyes are coordinated by $\mathrm{Zr}^{4+}$ and subsequently a second component (such as a catalyst) can be grafted on the zirconium phosphonate layer. This latter strategy has been nicely implemented by Reisner and co-workers for the fabrication of a NiO based DSPEC for the reduction of protons into hydrogen. ${ }^{23}$ Although, these elegant strategies represent very important contributions in the field, they present, however, some limitations. One drawback of the electropolymerization strategy is the difficulty to finely control the amount of grafted catalysts (formation of oligomers of different lengths that can clog the pores). Concerning the zirconium phosphonate based approach, it is impossible to control the orientation of the components as it necessitates the use of a dye functionalized by multiple phosphonic acid groups, preventing thus to selectively bind the molecule by a specific end. Most efficient dyes are asymmetrical systems (often push-pull) and their ability to efficiently inject charges into the semiconductor and/or in the adjacent layer heavily depends of the moiety bound to the surface. ${ }^{24}$ Moreover, although the above ingenious procedures have strengthened the stability of the immobilized molecules on the metal oxide, the resulting assembly does not meet the stability requirements for long operation time. Therefore, there is a real need for new and more versatile approaches to improve the stability of photoelectrochemical systems. Towards this objective, we felt that the crosslinking of sensitizers with a click reaction based on two complementary, but different, reactive groups could bring valuable new features (Scheme 1). Click chemistry on mesoporous metal oxide electrodes was reported before with simple molecular systems, which were composed of an alkyl chains functionnalized with a single azide or alkyne group on one end and a carboxylic acid or alkosilane group as binding units on the other, but the enhanced stability upon cross-linking was never attempted. ${ }^{25-28}$ 

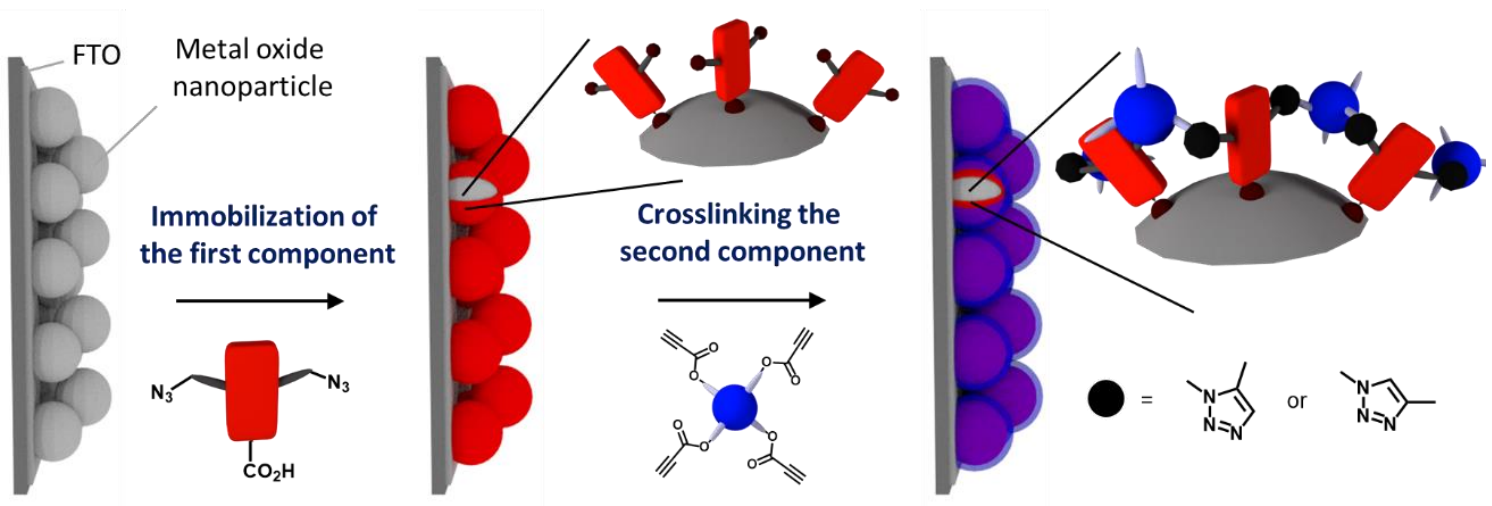

Scheme 1. Schematic representation of the copper free click chemistry methodology to crosslink the dyes over a mesoporous film.

More precisely, in this method the dye is functionalized by two or more azido groups, while a crosslinker contains several alkyne units to subsequently form triazole linkages via a Huisgen cycloaddition reaction. The advantages are the following. First, contrary to the polymerization approach, there is a good command of the final assembly, since homo-condensation of any component is prevented. Second, the reacting groups being different from the anchoring group, it becomes thus possible to control the attachment site of the sensitizer to the SC surface. Finally, if the activation of the reacting groups is based on a smooth heating, as it is the case in the procedure presented thereafter, the approach would present a broad scope as it would avoid irradiating the sensitizers with energetic radiations such as UV light or applying an electric potential to the film, which necessarily imposes that the sensitizers are highly stable in these quite harsh conditions.

As click chemistry reaction, we have selected the copper-free thermally induced Huisgen 1,3-dipolar cycloaddition between an electron deficient alkyne and an azide, a strategy which we have employed before to crosslink non-linear optical chromophores into polymer matrices to stabilize their orientation into electro-optic devices ${ }^{29}$ and also by others for different purposes..$^{30-33}$ Copper-free Huisgen reaction is a particularly valuable method for the envisioned applications of DSSC and DSPEC, because it is well accepted that metal cations can bind and intercalate into metal oxides surface and consequently modify the electronic properties of the semiconductor altering thus the performances of the photoelectrochemical cells. ${ }^{34,} 35$ Moreover, the absence of a metal complex or metal salt to activate the crosslinking reaction avoids metal scrambling when this approach will be used to click a catalyst above the dyes for DSPEC applications. ${ }^{36,37}$ To test the viability of this crosslinking strategy based on copper-free Huisgen reaction, we have prepared the two diketopyrrolopyrrole (DPP) dyes $\mathbf{1}$ and $\mathbf{2}$, which are substituted with two azido groups as sensitizers and a tetralkyne $\mathbf{3}$ as crosslinking agent (Figure 1). The synthesis of these two new dyes is described in the supporting information materials (Schemes S1-S2). DPP dyes are interesting candidates for this purpose, because they are efficient sensitizers for both n-type semiconductors (such as $\left.\mathrm{TiO}_{2}\right)^{38-40}$ and p-type semiconductors (such as $\mathrm{NiO}){ }^{41},{ }^{42}$ they are photochemically stable and can be easily functionalized by several synthetic methods. ${ }^{43}$ DPP 1 is better suited to sensitize $\mathrm{TiO}_{2}$, while DPP $\mathbf{2}$, which bears anchoring groups on the electron rich moiety, was specifically prepared to serve as sensitizer for NiO. DPP1 and DPP2 are orange-red compounds exhibiting a broad absorption band in the visible located around $560 \mathrm{~nm}$, in agreement with those reported with similar diketopyrrolopyrrole derivatives. ${ }^{41,}{ }^{44}$ The absorption spectra of DPP $\mathbf{1}$ and $\mathbf{2}$ are shown in Figures S1-S2 and the spectroscopic data are gathered in Table S1 in ESI. The redox potentials of the dyes were determined by cyclic voltammetry to calculate the Gibbs free energies of the electron injection into $\mathrm{TiO}_{2}$ conduction band and of the hole injection into $\mathrm{NiO}$ 
valence band from the singlet excited state of DPP1 and DPP2 respectively (Table S2). Both photoinduced charge injection reactions are strongly exergonic and therefore thermodynamically favorable, confirming that these dyes are suitable to sensitize these semiconductors. Likewise, the dye regeneration reactions display large driving forces with the two redox mediators (iodide/triiodide and cobalt complexes) used in this study (Table S2).
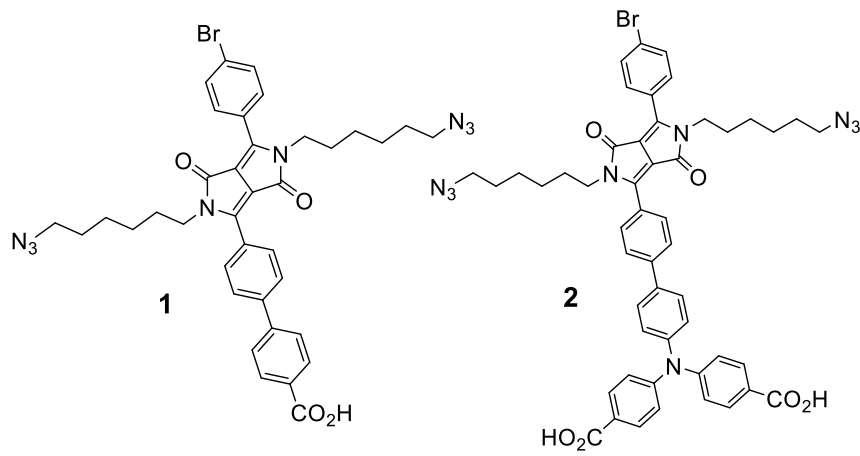

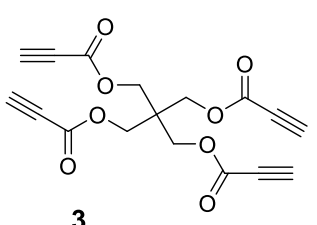

3

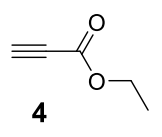

Figure 1. Structures of the components described in this study.

The dye $\mathbf{1}$ or $\mathbf{2}$ were initially grafted on the surface of a nanocrystalline film of the semiconductor and then it was efficiently thermally crosslinked with the tetraalkyne 3 after a gentle heating (for 60 min. at $90^{\circ} \mathrm{C}$ or for $15 \mathrm{~min}$. at $140^{\circ} \mathrm{C}$ ) of the electrode immersed into an orthodicholorobenzene (ODCB) solution of $\mathbf{3}$ (see experimental part for details). Interestingly, electro-deficient alkynes such as propiolate esters (compound $\mathbf{3}$ ) are quite reactive with azides and avoid using a catalyst. ${ }^{30,33,45,46} \mathrm{After}$ rinsing the electrodes, the progress of the cycloaddition of the reaction between $\mathbf{1}$ or $\mathbf{2}$ with $\mathbf{3}$ was monitored by attenuated total reflectance infrared spectroscopy (ATR-IR).
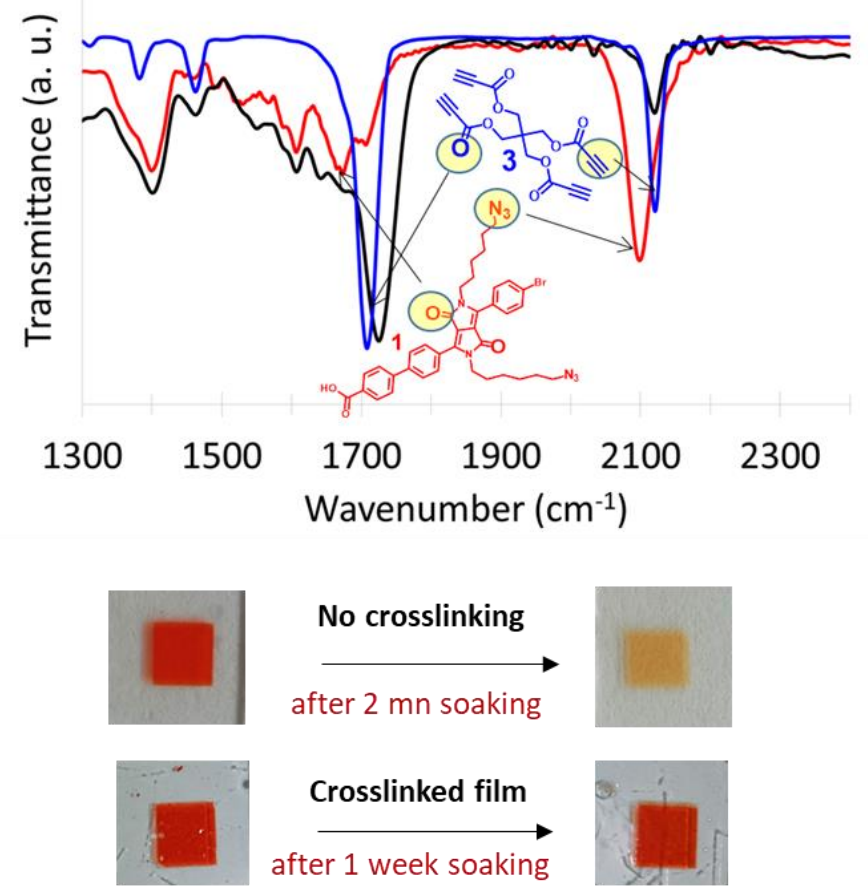

Figure 2. Top: ATR-IR spectra of DPP 1 grafted on $\mathrm{TiO}_{2}$ film before crosslinking (red) and after crosslinking (black) with 3. The blue trace corresponds to the ATR-IR spectrum of $\mathbf{3}$ powder. Bottom: Pictures of the $\mathrm{TiO}_{2}$ electrodes coated with dye $\mathbf{1}$ non-crosslinked and crosslinked with $\mathbf{3}$ before and after soaking into a solution of DMF/phenyl phosphonic acid (100 mM). 
The ATR-IR spectra (Figure 2 for $\mathrm{TiO}_{2}$ based photoanode and Figure $\mathrm{S} 3$ for NiO based photocathode) show that the intensity of the azido stretching bands has completely disappeared after heating, while that of the alkyne is visible meaning that there are some unreacted alkyne groups in the film. On the other hand, the stretching bands of the ester groups of the crosslinking agent 3 and that of the lactam of the DPP 1 or $\mathbf{2}$ (both around $1700 \mathrm{~cm}^{-1}$ ) are still clearly visible, proving that these moieties are present on the surface of the film. This result is consistent with the presence of four alkyne groups in $\mathbf{3}$ relative to only two azides on the dyes $\mathbf{1}$ or $\mathbf{2}$. The ATR-IR spectrum of the DPP $\mathbf{2}$ grafted on the electrode was not modified after heating in the crosslinking conditions $\left(15 \mathrm{~min}\right.$. at $140^{\circ} \mathrm{C}$ in orthodichlorbenzene) in absence of the cross-linker 3 (Figure S4). This indicates that the azido groups are stable in these conditions and do not degrade upon heating at $140^{\circ} \mathrm{C}$ for $15 \mathrm{~min}$.

To shed more light on the crosslinking reaction, we have reacted DPP 1 with the ethyl-propiolate ester 4 in ODCB solution with the same conditions as used for the photoelectrodes and we have analyzed the products of the reaction by ${ }^{1} \mathrm{H}$ NMR spectroscopy and mass spectrometry (Scheme S3 and Figures S5-S6). Previous studies have shown that the chemical shift of the triazole proton and that of the $\mathrm{CH}_{2}$ in alpha position to the triazole have different chemical shifts, permitting thus to determine the regioselectivity of the cycloaddition reaction. ${ }^{33,45,47,48}$ In solution, the reaction between DPP 1 and the mono alkyne 4 in the same conditions as those used for crosslinking led to the formation of two triazole isomers and therefore of potentially 4 different compounds (Scheme S3). Although the presence of four isomers might have little impact on the properties of the photoelectrochemical cells, it is interesting to notice that the ${ }^{1} \mathrm{H}$ NMR spectrum clearly reveals that the 1,4-triazole is preferentially formed $(75 \%)$ over the 1,5 -triazole $(25 \%)$. The selectivity of the Huisgen reaction with electron deficient alkynes was previously observed and is attributed to the polarization of the alkyne, which favors the pairing with the negatively charged nitrogen of the azide connected to the carbon chain. ${ }^{33 \text {, }}$ 45, 47, 48 The mass spectrum confirms the identity of the expected DPP 5 product in which the two azido groups were replaced by triazole units (Figure S6). To complete the characterizations of the click reaction products on the mesoporous electrodes, the $\mathrm{TiO}_{2}$ and $\mathrm{NiO}$ films, respectively coated with DPP 1 and DPP 2, were analyzed by Time-of-Flight Secondary Ion Mass Spectrometry (ToF-SIMS). ToF-SIMS consists in sputtering the surface with an ion beam of argon and collecting and analyzing the exact mass of the ejected secondary ions by a time of flight analyzer. Among the various meaningful fragments detected by ToF-SIMS, we can mention the most interesting following ones. Before crosslinking, the analyses of $\mathrm{TiO}_{2}$ and $\mathrm{NiO}$ electrodes coated with the respective dyes $\mathbf{1}$ and $\mathbf{2}$, show the $\mathrm{C}_{2} \mathrm{~N}^{-}$organic fragment at $\mathrm{m} / \mathrm{z}=38.004$ coming from the DPP dye (Figures S8-S9). However, the relative intensity of this signal is strongly enhanced after crosslinking, which is consistent with the formation of triazole rings bringing additional $\mathrm{C}_{2} \mathrm{~N}^{-}$fragments. Another valuable information drawn from ToF-SIMS experiments are coming from the observation of an inorganic fragment from the SC. For the $\mathrm{TiO}_{2}$ photoanodes, the $\mathrm{TiO}_{3}{ }^{-}$fragment at $\mathrm{m} / \mathrm{z}=95.934$ can be clearly detected, but its intensity is significantly diminished after crosslinking showing that the accessibility to the surface to the ion beam has been restricted probably by the physical barrier created by the network of triazole linkages (Figure S10). For $\mathrm{NiO}$ photocathodes, both fragments of $\mathrm{Ni}^{-}$at $\mathrm{m} / \mathrm{z}=57.935$, and $\mathrm{NiO}^{-}$at $\mathrm{m} / \mathrm{z}=73.927$ could be observed, but again the relative intensity of these two fragments considerably shrunk after crosslinking, which is consistent with a lower diffusion of the ion beam towards the NiO surface (Figures S11-S12). Taken all together, these results reveal that propiolate esters in solution (such as molecules 3 or 4 ) can smoothly react with the azido groups of a surface bound DPP dye to form triazole rings with about $75 \%$ selectivity towards the 1,4-isomer via thermal copper-free Huisgen reaction directly conducted on nanocrystalline metal oxide films of $\mathrm{TiO}_{2}$ or $\mathrm{NiO}$ (Scheme 1).

To investigate the ability of the crosslinking process to prevent the sensitizers from leaching, the nanocrystalline films of $\mathrm{TiO}_{2}$ or $\mathrm{NiO}$ coated with the dyes $\mathbf{1}$ or $\mathbf{2}$ were soaked into a DMF solution 
containing $100 \mathrm{mM}$ of phenyl phosphonic acid before and after cross-linking and the absorption spectra of the solution were measured over time (Figures S13-S14). These DPP dyes $\mathbf{1}$ and $\mathbf{2}$ being hydrophobic, DMF solvent was a much more relevant medium than water to assess the stability of the crosslinked films, because $\mathbf{1}$ and $\mathbf{2}$ are insoluble in water. Moreover, we have previously shown that phenyl phosphonic acid is a strong competitor to dyes bound via carboxylic acid anchors since exposition of a stained film to a DMF solution of phenyl phosphonic induces a rapid desorption of the dyes within few minutes. ${ }^{49}$ When $\mathrm{TiO}_{2}$ or NiO electrodes, respectively coated with DPP 1 or DPP $\mathbf{2}$, were soaked into a $100 \mathrm{mM}$ of phenyl phosphonic acid DMF solution, their initial deep red coloration disappears in less than 5 minutes and the DMF solution turns yellow (Figures 2 and S13-S14). In contrast, when the DPP dyes $\mathbf{1}$ or $\mathbf{2}$ were initially crosslinked with $\mathbf{3}$ and then dipped in the phenyl phosphonic acid DMF solution, the $\mathrm{TiO}_{2}$ or $\mathrm{NiO}$ films remained strongly colored and the DMF solution stayed colorless for several days, since less than $10 \%$ of the immobilized dyes have leached into the solution. These experiments clearly demonstrate that the above crosslinking procedure highly reduces the desorption of the grafted dyes when exposed to harsh desorption conditions. The increased stability is certainly the consequence of the chelate effect (dyes bound by multiple anchoring points), the insolubility of the resulting dye network and the lower accessibility of the phenyl phosphonic acid to the semiconductor surface. Indeed, when the DPP dye 1 was crosslinked with ethyl-propiolate ester 4, more than $85 \%$ of the dyes leach from the $\mathrm{TiO}_{2}$ surface within 10 minutes of soaking the electrode into the phenylphosphonic acid DMF solution almost as fast as the non-crosslinked film (Figure S15).

The $\mathrm{TiO}_{2}$ mesoporous electrodes coated with pristine DPP $\mathbf{1}$ and crosslinked with $\mathbf{3}$ were also investigated by cyclic voltammetry with a classical three electrodes setup. In the cathodic region a reversible reduction process was clearly observed at $-1.2 \mathrm{~V}$ vs SCE, which is attributed to the reduction of the DPP dye in agreement with the value measured with the dye in solution (Table S1). Interestingly, for the non-crosslinked electrode the intensity of the reduction current dropped very quickly to a very low value upon cycling, since after the fourth scan the current is less than $20 \%$ of that of the first scan (Figure S16). Inspection of the $\mathrm{TiO}_{2}$ electrode shows that the initial deep orange color turns almost white after 4 scans and detachment of the dye from the electrode upon cycling could be clearly seen (Figure S17). On the other hand, the same experiment made with a cross-linked electrode with $\mathbf{3}$, revealed that the intensity of the reduction process remains much more stable upon cycling since after 12 consecutive scans the intensity is still $90 \%$ of the initial one. Consistently the orange color of the $\mathrm{TiO}_{2}$ electrode has not faded away (Figure S16). These experiments indicate that electrochemical reduction of the grafted dye on $\mathrm{TiO}_{2}$ induces its fast leaching when it is simply bound with a carboxylic acid group, however, crosslinking the dye with $\mathbf{3}$ importantly increases the stability and keeps the electroactivity of the dye on the electrode.

The excited-state dynamic properties of DPP 1 and DPP 2, respectively grafted on $\mathrm{TiO}_{2}$ and $\mathrm{NiO}$ before and after cross-linking, were investigated by femtosecond transient absorption (TA) spectroscopy. The objective of this study was to assess the impact of the cross-linking on the charge injection process. Directly after $530 \mathrm{~nm}$ excitation of DPP 1 on $\mathrm{TiO}_{2}$, the TA spectra show positive absorption bands of the singlet excited state of the DPP sub-unit at 730 and $390 \mathrm{~nm}$ as well as negative ground-state bleach at $480 \mathrm{~nm}$ and stimulated emission features at longer wavelengths (Figure 4A). The stimulated emission decays in about 10 ps whereas the $730 \mathrm{~nm}$ band transforms into a broader band centered around $700 \mathrm{~nm}$ that can be attributed to radical cation of DPP, ${ }^{50,51}$ generated upon charge injection into $\mathrm{TiO}_{2}$. The charge-separated state decays partially in about $300 \mathrm{ps}$ and then remains almost constant up to $2 \mathrm{~ns}$, the upper limit of the experimental time window. The TA spectra recorded with DPP 1 on $\mathrm{TiO}_{2}$ after cross-linking do not exhibit any significant difference in shape (Figure S18) and dynamics (Figure 4C). Global analysis of the TA data assuming a series of consecutive exponential steps 
with increasing time constants results in almost identical evolution-associated difference spectra and time constants with and without cross-linker (Figure S19).
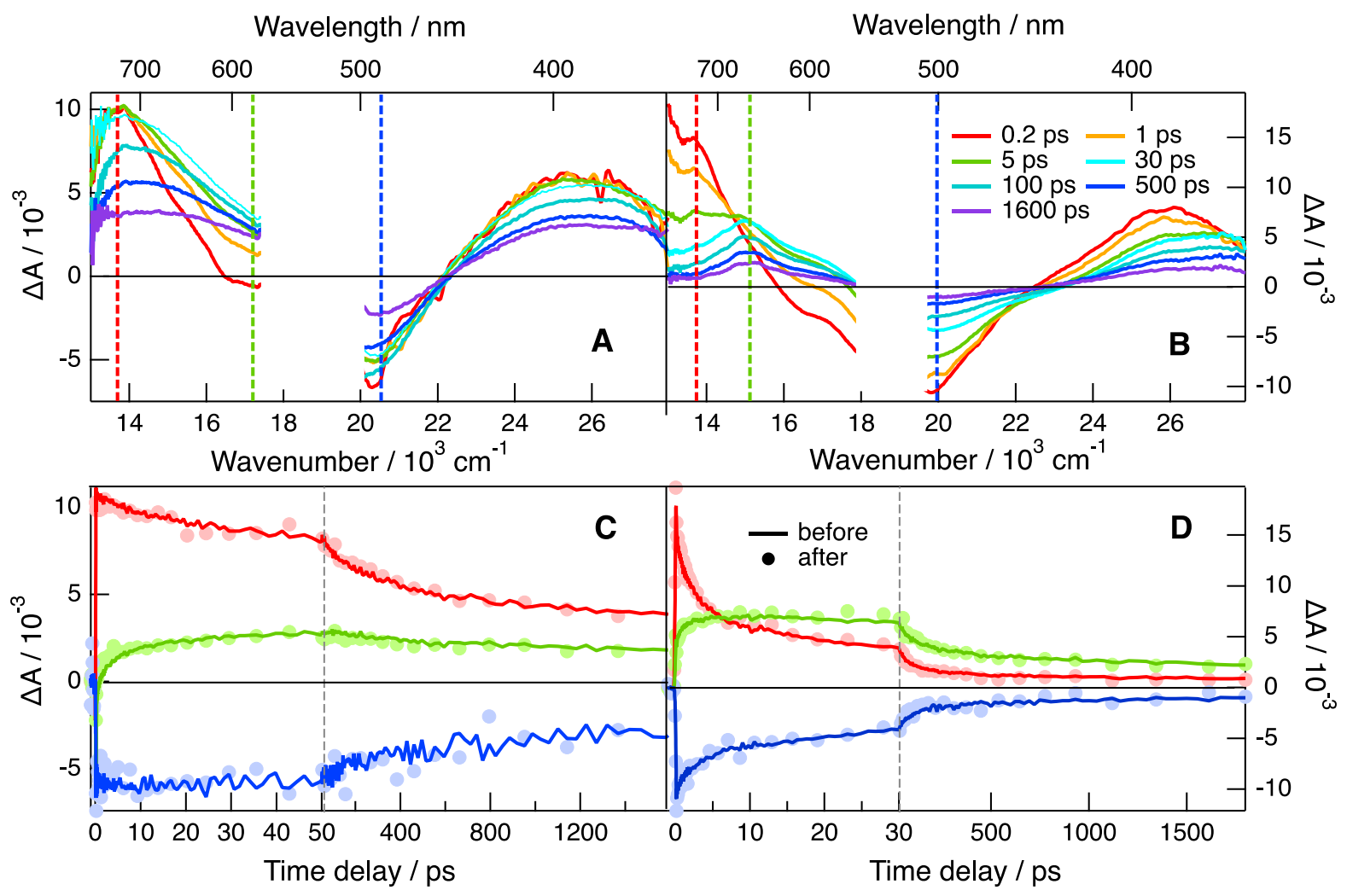

Figure 4: (Top) Transient absorption spectra measured at different time delays after $530 \mathrm{~nm}$ excitation of DPP 1 on $\mathrm{TiO}_{2}$ (A) and DPP 2 on NiO (B) before cross-linking with 3. Time dependence of the signal intensity at the wavelengths shown by dashed line in $\mathrm{A}$ and $\mathrm{B}$ for DPP 1 on $\mathrm{TiO}_{2}$ (C) and DPP 2 on NiO (D) before (solid lines) and after (symbols, only every fifth point is shown) cross-linking with 3.

Similarly, cross-linking of DPP 2 on NiO has no significant impact on the excited-state dynamics of the films (Figures 4B,D, and S18-S19). The early TA spectra are similar to those measured with DPP 1 on $\mathrm{TiO}_{2}$ and can thus be assigned to the electronic excited state of the DPP sub-unit. These features decay in about $5 \mathrm{ps}$, whereas a positive band appears at $660 \mathrm{~nm}$. The latter can be attributed to the radical anion of DPP, ${ }^{52}$ generated upon hole injection into the NiO valence band. After a partial decay in 60 ps, the charge-separated state persists to timescale over $2 \mathrm{~ns}$. These measurements demonstrate that the charge injection reactions into the SCs are not modified after crosslinking.

Finally, the pristine $\mathrm{TiO}_{2}$ and $\mathrm{NiO}$ mesoporous films coated respectively with DPP 1 and DPP 2 as well as those crosslinked with $\mathbf{3}$ were then used as photoelectrodes to construct DSSCs with the classical iodide/triiodide or the cobalt(III/II) complexes redox mediators (see Figure S7 in ESI for the structures of the redox mediators). The average metrics of at least six independent crosslinked and noncrosslinked DSSCs are gathered in Table 1 and the current/voltage characteristics are shown in Figures S20-S23. 
Table 1. Photovoltaic performances of the DSSCs recorded under simulated sunlight AM1.5 $\left(100 \mathrm{~mW} / \mathrm{m}^{2}\right) . \mathrm{w} / \mathrm{o}=$ without cross-linking and with = after copper-free crosslinking with 3.

\begin{tabular}{|c|c|c|c|c|c|c|}
\hline Electrode & & Electrolyte & $\begin{array}{c}\mathrm{J}_{\mathrm{SC}} \\
\left(\mathrm{mA} / \mathrm{cm}^{2}\right)\end{array}$ & $\begin{array}{l}V_{O C} \\
(m V)\end{array}$ & $\begin{array}{l}F F \\
(\%)\end{array}$ & $\begin{array}{l}\text { PCE } \\
(\%)\end{array}$ \\
\hline \multirow{4}{*}{$\mathrm{TiO}_{2} / \mathrm{DDP} 1$} & $w / o$ & \multirow{2}{*}{$\mathrm{I}_{3}^{-} / \mathrm{I}^{-}$} & $4.98 \pm 0.5$ & $470 \pm 10$ & $68 \pm 1$ & $1.58 \pm 0.06$ \\
\hline & with & & $5.37 \pm 0.3$ & $475 \pm 11$ & $70 \pm 1$ & $1.77 \pm 0.07$ \\
\hline & $w / o$ & \multirow{2}{*}{$\mathrm{Co}\left(\right.$ bpy) $3^{I 11 / 11}$} & $2.20 \pm 0.1$ & $586 \pm 9$ & $61 \pm 5$ & $0.80 \pm 0.08$ \\
\hline & with & & $2.70 \pm 0.1$ & $590 \pm 5$ & $71 \pm 1$ & $1.10 \pm 0.05$ \\
\hline \multirow{4}{*}{ NiO/DDP2 } & $w / o$ & \multirow{2}{*}{$\mathrm{I}_{3}{ }^{-} / \mathrm{I}^{-}$} & $2.02 \pm 0.1$ & $89 \pm 4$ & $33 \pm 1$ & $0.060 \pm 0.008$ \\
\hline & with & & $1.23 \pm 0.4$ & $151 \pm 8$ & $38 \pm 1$ & $0.070 \pm 0.006$ \\
\hline & $w / o$ & \multirow{2}{*}{$\mathrm{Co}\left({ }^{\mathrm{t} B \mathrm{~B}_{2} \mathrm{bpy}}\right)_{3}{ }^{11 / / I I}$} & $0.88 \pm 0.08$ & $133 \pm 6$ & $25 \pm 2$ & $0.023 \pm 0.004$ \\
\hline & with & & $0.87 \pm 0.1$ & $200 \pm 5$ & $28 \pm 1$ & $0.048 \pm 0.008$ \\
\hline
\end{tabular}

The photovoltaic performances of the crosslinked cells are higher than the non-crosslinked ones for both $\mathrm{TiO}_{2}$ and $\mathrm{NiO}$ based DSSCs, whatever the redox mediator used in the electrolyte. For $\mathrm{TiO}_{2}$ based DSSCs, this mostly results from a larger short circuit photocurrent density (Jsc) with the crosslinked dyes. On the other hand, the crosslinked NiO based p-DSSCs display much higher Voc with both redox mediators. However, on $\mathrm{NiO}$ based p-DSSCs the iodine based electrolyte gives lower Jsc after crosslinking. Jsc is controlled by the light harvesting efficiency (LHE), the charge injection quantum yield, the charge recombination reactions and by the charge collection efficiency. LHE is certainly not the cause of the lower Jsc, because the absorbance has not changed after crosslinking. Likewise, the hole injection efficiency is most certainly not affected by the crosslinking, because the current density is not diminished after crosslinking with the cobalt electrolyte. If an enhancement of the charge recombination reactions was the cause of the lower Jsc, first the Voc would be decreased as well, which is the reverse and second it would occur with the cobalt electrolyte, which is not the case either. Logically, we can therefore interpret the lower Jsc as a consequence of the lower efficiency of the dye regeneration step, which directly reduces the charge collection efficiency. It was previously reported by $\mathrm{Xu}$ and co-workers, ${ }^{53}$ that electron deficient triazoles similar to those involved in this study can make anion- $\pi$ interaction with iodide. This hypothesis is supported by observing that the ${ }^{1} \mathrm{H}$ NMR chemical shift of triazole of the reference compound benzyl-1,2,3-triazole-4-carboxylic acid methyl ester $\mathbf{1 5}$ was down-field shifted upon addition of $\mathrm{Bu}_{4} \mathrm{NI}$ in the NMR tube (Figure S24). As a result, after crosslinking the concentration of iodide is certainly raised in the vicinity of the DPP $\mathbf{2}$ and might therefore hinder the approach of triiodide and consequently limit the charge regeneration efficiency of the reduced DPP after hole injection. In both devices, the increase of the Voc after crosslinking is most probably due to lower interfacial charge recombination coming from lower access of the redox mediator to the surface semiconductor. Indeed, inspection of the current/voltage characteristics of the solar cell 
recorded in the dark demonstrate that current of the crosslinked solar cells is significantly lower than the non-crosslinked ones (Figures S20-S23). Interfacial charge recombination between the redox mediator and the hole in $\mathrm{NiO}$ is known to be a major source of energy loss in p-DSSCs, ${ }^{54}$ therefore it is not unexpected that the reduction of this process impacts more importantly NiO based solar cells than $\mathrm{TiO}_{2}$ DSSCs.

In an another set of experiments, the DPP dyes $\mathbf{1}$ and $\mathbf{2}$ were cross-linked with $\mathbf{3}$ with the classical copper-catalyzed protocol by heating the photoelectrode for 10 minutes at $30^{\circ} \mathrm{C}$ in a DMF solution with $\mathrm{Cu}\left(\mathrm{SO}_{4}\right) \cdot 5 \mathrm{H}_{2} \mathrm{O}$, sodium ascorbate in presence of the tris(benzyltriazolylmethyl)amine (TBTA) ligand. ${ }^{55}, 56$ The completion of the reaction was confirmed by the ATR-IR spectroscopy (Figures S25S26). The results of the photovoltaic performances of the solar cells made with the $I_{3}^{-} / l^{-}$redox couple are gathered in Table S3. Clearly, the conditions of copper catalyzed Huisgen cycloaddition, although conducted in mild conditions, negatively impact the performances of the solar cells since the PCEs are notably lower than those measured with the thermal crosslinking activation. For $\mathrm{TiO}_{2}$ based solar cells, both Jsc and Voc were diminished upon cross-linking. Interestingly, the performances of photocathodes with $\mathrm{NiO}$ are less degraded than those with the photoanodes based on $\mathrm{TiO}_{2}$, because only the Jsc was decreased after copper-catalyzed cross-linking. This result is consistent with the upward shift of the valence band of $\mathrm{NiO}$ upon insertion of copper cation into the lattice as it was previously reported. ${ }^{57,58}$ Another possibility, is the presence of remaining $\mathrm{Cu}(\mathrm{II})$ salt, which is a paramagnetic metal that could quench the excited state of the dye and consequently diminishes the charge injection quantum yield as shown by Hanon and co-workers. ${ }^{59}$

Overall, crosslinking the sensitizers under copper-free conditions lead to an increase of the photovoltaic performances of all the DSSCs with both electrolytes. For NiO photocathodes, the Jsc is decreased owing to most probable iodide association with triazole, but it is compensated with the increase of Voc and ff. Crosslinking of the dyes with copper(I) catalysis is also possible, but the resulting solar cells exhibit lower performances, showing that copper has poisoned the devices.

In conclusion, we have shown that thermal copper-free Huisgen reaction is a simple and potentially very useful strategy to crosslink the dyes after their chemisorption on a nanocrystalline film of a semiconductor. It can be directly conducted on films of $\mathrm{TiO}_{2}$ or $\mathrm{NiO}$ electrodes between already bound sensitizers and electron deficient alkyne substrates such as propiolate ester derivatives. The latter can be prepared by a simple esterification reaction with propiolic acid, which is a cheap reagent. After crosslinking, the photoelectrodes made of sensitized $\mathrm{TiO}_{2}$ or $\mathrm{NiO}$ mesoporous films keep their initial photoelectrochemical properties, in spite of the fact that NiO DSSCs witness a drop of Jsc. More interestingly, the desorption of the immobilized dyes is heavily reduced compared to non-crosslinked films, as demonstrated by the desorption experiments with phenyl phosphonic acid and the cyclic voltammetry studies, highlighting thus the real potential of this strategy to maintain activity of photoelectrodes for applications where leaching of the dyes represents an issue. This is particularly true for photoelectrochemical devices such as DSSCs employing an aqueous electrolytes ${ }^{60}$ or for DSPECs in general. The above strategy can be most certainly generalized with many different dyes and other polyalkyne substituted molecules and probably various mesoporous films of metal oxides from n-type SCs $\left(\mathrm{TiO}_{2}\right), \mathrm{p}$-SCs ( $\left.\mathrm{NiO}\right)$ and transparent conductors (ITO) to even insulators $\left(\mathrm{ZrO}_{2}, \mathrm{Al}_{2} \mathrm{O}_{3}\right)$. More importantly, this approach opens the possibility to make "chemistry on the electrode" by functionalizing and crosslinking dyes in a single step after their grafting with any component such as electron acceptors or donors, antenna or catalysts in place of the passive crosslinking agent $\mathbf{3}$ employed here and to develop multifunctional hybrid photoelectrochemical cells.

Conflict of Interest: The authors declare no financial/commercial conflict of Interest. 
Acknowledgements: Région des Pays de la Loire is gratefully acknowledged for the financial support of these researches through the project "ClickChemHybrids" via the program LUMOMAT.

Supporting information available: Synthesis of the DPP dyes 1-2, absorption and emission spectra of the dyes in solution, Gibbs free energies of the charge transfer reactions on the SCs, reaction of DPP 1 with ethyl-propiolate ester, preparation and characterizations of the DSSCs, additional ToF-SilMS spectra, spectra of the desorption experiments, cyclic voltamogramms on $\mathrm{TiO}_{2}$ electrodes, additional transient absorption spectroscopy spectra, current/voltage characteristics of the solar cells, IR spectra of the electrodes after crosslinking, table of the photovoltaic performances of the DSSCs and ${ }^{1} \mathrm{H}$ and ${ }^{13} \mathrm{C}$ spectra of the new compounds.

\section{References}

1. A. Hagfeldt, G. Boschloo, L. Sun, L. Kloo and H. Pettersson, Chem. Rev., 2010, 110, 6595-6663.

2. D. L. Ashford, M. K. Gish, A. K. Vannucci, M. K. Brennaman, J. L. Templeton, J. M. Papanikolas and T. J. Meyer, Chem. Rev., 2015, 115, 13006-13049.

3. M. K. Brennaman, R. J. Dillon, L. Alibabaei, M. K. Gish, C. J. Dares, D. L. Ashford, R. L. House, G. J. Meyer, J. M. Papanikolas and T. J. Meyer, J. Am. Chem. Soc., 2016, 138, 13085-13102.

4. F. Odobel and Y. Pellegrin, J. Phys. Chem. Lett., 2013, 4, 2551-2564.

5. Z. Yu, F. Li and L. Sun, Energy Environ. Sci., 2015, 8, 760-775.

6. M. Yu, X. Ren, L. Ma and Y. Wu, Nat. Commun., 2014, 5, ncomms9103.

7. K. L. Materna, R. H. Crabtree and G. W. Brudvig, Chem. Soc. Rev., 2017, 46, 6099-6110.

8. L. Zhang and J. M. Cole, ACS Appl. Mater. Interfaces, 2015, 7, 3427-3455.

9. L. Li, L. Duan, F. Wen, C. Li, M. Wang, A. Hagfeldt and L. Sun, Chem. Commun., 2012, 48, 988990.

10. K. Hanson, M. K. Brennaman, A. Ito, H. Luo, W. Song, K. A. Parker, R. Ghosh, M. R. Norris, C. R. K. Glasson, J. J. Concepcion, R. Lopez and T. J. Meyer, J. Phys. Chem. C, 2012, 116, 14837-14847.

11. K. Hanson, M. K. Brennaman, H. Luo, C. R. K. Glasson, J. J. Concepcion, W. Song and T. J. Meyer, ACS Appl. Mater. Interfaces, 2012, 4, 1462-1469.

12. L. Wu, M. Eberhart, A. Nayak, M. K. Brennaman, B. Shan and T. J. Meyer, J. Am. Chem. Soc., 2018, 140, 15062-15069.

13. M. Fournier, D. A. Hoogeveen, S. A. Bonke, L. Spiccia and Alexandr N. Simonov, Sustainable Energy Fuels, 2018, 2, 1707-1718.

14. K. L. Materna, B. J. Brennan and G. W. Brudvig, Dalton Trans., 2015, 44, 20312-20315.

15. B. S. Veldkamp, W.-S. Han, S. M. Dyar, S. W. Eaton, M. A. Ratner and M. R. Wasielewski, Energy Environ. Sci., 2013, 6, 1917-1928.

16. J. Jiang, J. A. Spies, J. R. Swierk, A. J. Matula, K. P. Regan, N. Romano, B. J. Brennan, R. H. Crabtree, V. S. Batista, C. A. Schmuttenmaer and G. W. Brudvig, J. Phys. Chem. C, 2018, 122, 13529-13539.

17. S.-H. Park, J. Lim, I. Y. Song, N. Atmakuri, S. Song, Y. S. Kwon, J. M. Choi and T. Park, Adv. Energy Mater., 2012, 2, 219-224.

18. M. A. Desta, C.-W. Liao and S.-S. Sun, Chem. Asian J., 2017, 12, 690-697.

19. K.-Y. Liu, C.-Y. Ko, K.-C. Ho and K.-F. Lin, Polymer, 2011, 52, 3318-3324.

20. D. L. Ashford, A. M. Lapides, A. K. Vannucci, K. Hanson, D. A. Torelli, D. P. Harrison, J. L. Templeton and T. J. Meyer, J. Am. Chem. Soc., 2014, 136, 6578-6581.

21. J.-Y. Shao and Y.-W. Zhong, Inorg. Chem., 2019, 58, 3509-3517.

22. K. Hanson, D. A. Torelli, A. K. Vannucci, M. K. Brennaman, H. Luo, L. Alibabaei, W. Song, D. L. Ashford, M. R. Norris, C. R. K. Glasson, J. J. Concepcion and T. J. Meyer, Angew. Chem. Int. Ed., 2012, 51, 12782-12785.

23. M. A. Gross, C. E. Creissen, K. L. Orchard and E. Reisner, Chem. Sci., 2016, 7, 5537-5546.

24. A. Mishra, M. K. R. Fischer and P. Bäuerle, Angew. Chem. Int. Ed., 2009, 48, 2474-2499. 
25. L. Wu, M. Eberhart, B. Shan, A. Nayak, M. K. Brennaman, A. J. M. Miller, J. Shao and T. J. Meyer, ACS Appl. Mater. Interfaces, 2019, 11, 4560-4567.

26. S. Shah, M. C. Benson, L. M. Bishop, A. M. Huhn, R. E. Ruther, J. C. Yeager, Y. Tan, K. M. Louis and R. J. Hamers, J. Mater. Chem., 2012, 22, 11561-11567.

27. Y. Cao, E. Galoppini, P. I. Reyes and Y. Lu, Langmuir, 2013, 29, 7768-7775.

28. L. M. Bishop, J. C. Yeager, X. Chen, J. N. Wheeler, M. D. Torelli, M. C. Benson, S. D. Burke, J. A. Pedersen and R. J. Hamers, Langmuir, 2012, 28, 1322-1329.

29. C. Cabanetos, W. Bentoumi, V. Silvestre, E. Blart, Y. Pellegrin, V. Montembault, A. Barsella, K. Dorkenoo, Y. Bretonnière, C. Andraud, L. Mager, L. Fontaine and F. Odobel, Chem. Mater., 2012, 24, 1143-1157.

30. B. S. Min, H. B. Jeon, T. U. Jeong and S. Y. Kim, Polymer Chem., 2015, 6, 7913-7920.

31. X. Deng, C. Friedmann and J. Lahann, Angew. Chem. Int. Ed., 2011, 50, 6522-6526.

32. S. Schmitt, J. Hümmer, S. Kraus, A. Welle, S. Grosjean, M. Hanke-Roos, A. Rosenhahn, S. Bräse, C. Wöll, C. Lee-Thedieck and M. Tsotsalas, Adv. Funct. Mater., 2016, 26, 8455-8462.

33. H. Li, H. Wu, E. Zhao, J. Li, J. Z. Sun, A. Qin and B. Z. Tang, Macromolecules, 2013, 46, 39073914.

34. Y. Liu, A. Hagfeldt, X.-R. Xiao and S.-E. Lindquist, Sol. Energy Mater. Sol. Cells, 1998, 55, 267281.

35. L. A. Lyon and J. T. Hupp, J. Phys. Chem., 1995, 99, 15718-15720.

36. P. B. Pati, L. Zhang, B. Philippe, R. Fernández-Terán, S. Ahmadi, L. Tian, H. Rensmo, L. Hammarström and H. Tian, ChemSusChem, 2017, 10, 2480-2495.

37. N. Kaeffer, J. Massin, C. Lebrun, O. Renault, M. Chavarot-Kerlidou and V. Artero, J. Am. Chem. Soc., 2016, 138, 12308-12311.

38. F. Zhang, K.-J. Jiang, J.-H. Huang, C.-C. Yu, S.-G. Li, M.-G. Chen, L.-M. Yang and Y.-L. Song, J. Mater. Chem. A, 2013, 1, 4858-4863.

39. T. W. Holcombe, J.-H. Yum, Y. Kim, K. Rakstys and M. Graetzel, J. Mater. Chem. A, 2013, 1, 13978-13983.

40. J.-H. Yum, T. W. Holcombe, Y. Kim, K. Rakstys, T. Moehl, J. Teuscher, J. H. Delcamp, M. K. Nazeeruddin and M. Gratzel, Sci. Rep., 2013, 3, 2446.

41. Y. Farré, L. Zhang, Y. Pellegrin, A. Planchat, E. Blart, M. Boujtita, L. Hammarström, D. Jacquemin and F. Odobel, J. Phys. Chem. C, 2016, 120, 7923-7940.

42. Y. Farré, M. Raissi, A. Fihey, Y. Pellegrin, E. Blart, D. Jacquemin and F. Odobel, ChemSusChem, 2017, 10, 2618-2625.

43. M. Grzybowski and D. T. Gryko, Adv. Optical Mater., 2015, 3, 280-320.

44. J. Warnan, L. Favereau, Y. Pellegrin, E. Blart, D. Jacquemin and F. Odobel, J. Photochem. Photobiol., A, 2011, 226, 9-15.

45. V. M. Muzalevskiy, M. N. Mamedzade, V. A. Chertkov, V. A. Bakulev and V. G. Nenajdenko, Mendeleev Commun., 2018, 28, 17-19.

46. B. S. Min and S. Y. Kim, Macromol. Res., 2017, 25, 249-254.

47. E. M. Alexandrino, P. Buchold, M. Wagner, A. Fuchs, A. Kreyes, C. K. Weiss, K. Landfester and F. R. Wurm, Chem. Commun., 2014, 50, 10495-10498.

48. A. Earla, L. Li, P. Costanzo and R. Braslau, Polymer, 2017, 109, 1-12.

49. D. Ameline, S. Diring, Y. Farre, Y. Pellegrin, G. Naponiello, E. Blart, B. Charrier, D. Dini, D. Jacquemin and F. Odobel, RSC Adv., 2015, 5, 85530-85539.

50. M. Gora, S. Pluczyk, P. Zassowski, W. Krzywiec, M. Zagorska, J. Mieczkowski, M. Lapkowski and A. Pron, Synth. Metals, 2016, 216, 75-82.

51. P. E. Hartnett, S. M. Dyar, E. A. Margulies, L. E. Shoer, A. W. Cook, S. W. Eaton, T. J. Marks and M. R. Wasielewski, Chem. Sci., 2015, 6, 402-411.

52. T. Kim, W. Kim, O. Vakuliuk, D. T. Gryko and D. Kim, J. Am. Chem. Soc., 2020, 142, 1564-1573.

53. C.-Y. Wang, J.-F. Zou, Z.-J. Zheng, W.-S. Huang, L. Li and L.-W. Xu, RSC Adv., 2014, 4, 5425654262. 
54. L. Favereau, Y. Pellegrin, L. Hirsch, A. Renaud, A. Planchat, E. Blart, G. Louarn, L. Cario, S. Jobic, M. Boujtita and F. Odobel, Adv. Energy Mater., 2017, 7, doi: 10.1002/aenm.201601776.

55. P. K. B. Palomaki and P. H. Dinolfo, Langmuir, 2010, 26, 9677-9685.

56. M. C. Benson, R. E. Ruther, J. B. Gerken, M. L. Rigsby, L. M. Bishop, Y. Tan, S. S. Stahl and R. J. Hamers, ACS Appl. Mater. Interfaces, 2011, 3, 3110-3119.

57. S. M. McCullough, J. M. Evans, T. Moot, A. Taggart, L. Troian-Gautier and J. F. Cahoon, ACS Appl. Energy Mater., 2020, 3, 1496-1505.

58. B. Shan, B. D. Sherman, C. M. Klug, A. Nayak, S. L. Marquard, Q. Liu, R. M. Bullock and T. J. Meyer, J. Phys. Chem. Lett., 2017, 8, 4374-4379.

59. J. C. Wang, O. O. Ogunsolu, M. Sykora and K. Hanson, J. Phys. Chem. C, 2018, 122, 9835-9842.

60. F. Bella, C. Gerbaldi, C. Barolo and M. Grätzel, Chem. Soc. Rev., 2015, 44, 3431-3473. 